\title{
Single motherhood and neonatal and infant mortality in Sierra Leone, Burkina Faso and Burundi
}

\author{
C. Izugbara ${ }^{a, b, *}$ \\ ${ }^{a}$ Department of Sociology, University of Pretoria, South Africa \\ ${ }^{b}$ Human Economy Programme, University of Pretoria, South Africa \\ *Corresponding author. Department of Sociology, University of Pretoria, South Africa. Tel.: p27 612866977. E- \\ mail address: cizugbara@yahoo.com.
}

\begin{abstract}
Background

Childhood mortality is a stubborn problem and remains highest in Sub-Saharan Africa (SSA). Existing research on childhood mortality in SSA indicate that most of the childhood deaths are from preventable causes such as diarrhoea, pneumonia, measles, malaria, HIV and underlying malnutrition, acute respiratory infections, whooping cough, tuberculosis, bronchopneumonia, dirty feeding bottles and utensils, inadequate disposal of household refuse and poor storage of drinking water. However, insufficient attention has been given to maternal marital status and childhood mortality relationships. Understanding the implications of maternal marital status for childhood mortality can add to our knowledge of the correlates of neonatal and infant mortality and furnish insights to support the design and delivery of interventions to address the problem.
\end{abstract}

\section{Objective}

To document and examine the extent to which the association between neonatal and infant mortality varies between single and ever-married mothers in Sierra Leone, Burkina Faso, and Burundi. A single mother is defined in this study as a woman who has either lived with a partner, married before, widowed, separated during the survey periods and has given at least one life birth. Ever-married woman is woman who has been married at least once in their lives although their current marital status may not be married.

\section{Study design}

Data for this study were drawn from the latest Demographic and Health Surveys (DHS) in Burkina Faso, Sierra Leone and Burundi. The selected datasets came from 2010 Burkina Faso DHS (BFDHS), 2008 Sierra Leone DHS (SLDHS) and 2010 Burundi DHS (EDSB II).

\section{Methods}

The relevant data for this study (women age 15-49 years who had at least one live birth within the five years preceding the survey) were extracted from the whole dataset of each country (Burkinabe $(n=17,087)$, Sierra Leonean $(n=7374)$ and Burundian $(n=9389)$. Univariate and multivariate statistical analyses were used to assess the association between 
neonatal and infant mortality and maternal marital status. All data were analysed using STATA Version 11.

\section{Results}

The multivariate logistic regression analyses yielded significantly increased risk of neonatal and infant mortality among single mothers.

\section{Conclusions}

Neonates and infants of single mothers are at increased risk of neonatal and infant mortality compared to those of ever-married women.

\section{Keywords}

Single motherhood; Neonatal and infant mortality; Sierra Leone; Burkina Faso, and Burundi

\section{Introduction}

Childhood mortality is a stubborn problem and remains highest in Sub-Saharan Africa (SSA). ${ }^{1 \text { and } 2}$ In 2013, the childhood mortality rate in SSA was 92 deaths per 1000 live births, more than 15 times the average rate in developed nations ( 6 deaths per 1000 live births). ${ }^{12}$ Analyses of recent trends however show that SSA is making progress in slowing down childhood mortality rates. For instance, average annual rate of reduction in childhood mortality has accelerated from 1.2\% a year over 1990-1995 to 3.9\% over 2005-2012. ${ }^{1}$ and 12 Apparently, much has been achieved in improving child survival in SSA but definitely much remains to be done.

A review of literature on childhood mortality in SSA indicate that most of the childhood deaths are from preventable causes such as diarrhoea, ${ }^{3}$ pneumonia, measles, malaria, ${ }^{4} \mathrm{HIV}$ and underlying malnutrition, ${ }^{5}$ acute respiratory infections, ${ }^{6}$ and 7 whooping cough, tuberculosis, ${ }^{8}$ bronchopneumonia, ${ }^{4}$ dirty feeding bottles and utensils, inadequate disposal of household refuse and poor storage of drinking water. ${ }^{9}$ Mounting evidence has also shown that childhood mortality rates vary by socio-economic and bio-demographic characteristics. For instance, women with low or no education; $;^{13 \text { and } 14}$ women in lower wealth quintile $;^{1 \text { and } 15}$ women who reside in rural areas; ${ }^{1}$ and 16 women who have poor or no access to electricity; ${ }^{17 \text { and } 18}$ women who delay initiation of breastfeeding; ${ }^{19}$ and 20 women who did not complete child immunization; ${ }^{21}$ women who use illicit substances during pregnancy; ${ }^{22}$ women who are indigenous religious worshippers; and older fathers tend to have higher childhood mortality. ${ }^{1 \text { and } 23}$

In other studies birth intervals, mother's age at birth, number of living children, sex of the child and unintended births are significantly associated with infant and neonatal mortality. ${ }^{1}$ 
Some other researchers examined the interaction between intimate partner violence and childhood mortality. ${ }^{24}$ In such studies, ${ }^{25}$ it was observed that infant and neonatal mortality was greater among children whose mothers experienced intimate partner violence versus those whose mothers did not experience intimate partner violence. The primary explanation of the influence of violence against women on the risk of neonatal and infant mortality is the possible constraining effect of such violence upon women's ability to physically and emotionally care and provide for their children's basic needs. ${ }^{26}$

Little is known about maternal marital status and early children health outcome relationships. In the available literature, single mothers are seen as a sociodemographic risk factor associated with smoking during pregnancy, and maternal depression. ${ }^{27}$ Children of single mothers fare worse with respect to cognitive development, ${ }^{28}$ educational outcomes, ${ }^{29}$ and behavioural adjustment. ${ }^{30}$ In Kenya, ${ }^{31}$ it was found that children of never-married and formerly married women had higher rates of wasting and were less likely to receive a complete course of polio vaccination.

Most studies have been unable to distinguish cohabiting mothers from married mothers, for instance, in a study of smoking during pregnancy in Sweden, ${ }^{32}$ the authors grouped married and cohabiting mothers together. Other studies used indicators of female-headed households as a measure of maternal marital status. ${ }^{33}$ However, female household heads and single mothers differ in important ways. ${ }^{34}$ For example, measures of female-headed households generally does not capture what Buvinic and Gupta called 'subfamilies', ${ }^{35}$ which are made up of single mothers and their children who live within male-headed households. Lastly, a large portion of female-headed households in some countries consist of married women with migrant husbands who send their families substantial remittances. ${ }^{36}$ Put simply, a single mother family is where a woman who has had at least one dependent child and is living alone without a partner. ${ }^{37}$ Never with a partner, married before, widowed, separated and living with at least one dependent child is the core basis in the definition of single mother family. ${ }^{38}$ These data limitations may partially or fully explain the surprisingly weak and inconsistent evidence that children living in female-headed households suffer from poorer health than children living in male-headed households. ${ }^{1}$

There are limited studies that have examined the relationship between single motherhood and neonatal and infant mortality in Africa. As a result, precious little is known about whether mortality rates among children aged $<1$ year of single mothers differ. For example, we do not know whether or to what extent differences in neonatal and infant mortality rates exist between ever-married and single mothers. The Child Health Epidemiology Reference Group estimated that $40.3 \%$ of 7.6 million childhood deaths in 2010 (3.1 million deaths) occurred in children aged $>1$ year. ${ }^{39}$ In all, conclusive evidence shows however that early childhood health is the most important phase in life which determines the quality of health, well-being, learning and behaviour across the life span. It is a period of great opportunity, but also of great vulnerability to negative influences. ${ }^{12}$ Studies also show that scores of the health and well-being problems we see in adults such as obesity and its associations such as diabetes and heart disease, mental health problems, criminality, family violence, poor literacy, unemployment and welfare dependency have their origins in pathways that begin much earlier in life, often in early childhood. ${ }^{40}$ However, this does not mean that what happens in early childhood invariably determines later development; but 
rather early experiences set children on developmental paths that become progressively more difficult to modify as they get older. ${ }^{41}$ This paper aims to document and examine the extent to which the association between neonatal and infant mortality varies between single and ever-married mothers in Sierra Leone, Burkina Faso and Burundi.

\section{Methods}

Data for this study are drawn from the latest Demographic and Health Surveys (DHS) in Burkina Faso, Sierra Leone and Burundi. The selected datasets came from 2010 Burkina Faso DHS (BFDHS), 2008 Sierra Leone DHS (SLDHS) and 2010 Burundi DHS (EDSB II). The selected datasets are the most recent and comprehensive of all the demographic and health surveys conducted in the selected countries. The Demographic and Health Surveys are routinely conducted by Measure DHS in several countries using similar methodology. Primary sampling unit (PSU) is regarded in the DHS as a cluster and this is defined on the basis of Enumeration Areas (EAs). Under the DHS programme, samples for the selected surveys were drawn using stratified two-stage cluster design consisting of 574 clusters in Burkina Faso, 336 clusters in Sierra Leone, and 376 clusters in Burundi.

Nationally representative households were selected in each country and all women age 1549 years in those households were interviewed. The relevant data for this study (women age 15-49 years who had at least one live birth within the five years preceding the survey) were extracted from the whole dataset of each country. Burkinabe $(n=17,087)$, Sierra Leonean $(n=7374)$ and Burundian $(n=9389)$. Births recode data of the Demographic and Health Survey was utilized for each of the three countries. Multiple births were excluded from the present analysis. Weighting factors were applied in the analysis to adjust for oversampling or under sampling of some locations in the selected countries. The outcome variables for this study are neonatal and infant mortality. The outcome variables were measured as the duration of survival since birth in months. The children's survival status and the age at death in months (if the child had died) or the last month they were known to be alive (if child was still living at the time of the survey) were combined to generate the outcome variables. Children known to have died (i.e. non-censored observation) were regarded as the cases, whereas children who were still alive at the time of the survey were treated as rightcensored. Right censoring occurs when a subject leaves the study before an event occurs, or the study ends before the event has occurred ${ }^{42}$

The key explanatory variable in this study is single motherhood - categorized as (1) YES (2) NO. Adjustments were also made in the analysis for the effects of characteristics that are established in the literature as important predictors of neonatal and infant mortality in the developing societies. These include maternal education [categorized as (1) none, (2) primary, (3) secondary or higher]; wealth index [grouped as (1) low, (2) middle, (3) high]; place of residence [categorized as (1) urban, (2) rural]; number of living children [categorized as (1) 0-5, (2) 6 and above]; number of children ever born [categorized as (1) $0-4,(2) 5-9,(3) 10$ and above]; and maternal age at childbirth [grouped as (1) 15-24 years, (2) 25-34 years, (3) 35-49 years]. ${ }^{43}$

Data analysis and management in this study was done using Stata version 11 . Bivariate associations were used to examine the association between the independent socio- 
economic and demographic variables and the dependent variable, single motherhood. In order to examine such an association, Pearson Chi-squared test assisted in identifying factors that are significantly associated with single motherhood. The final stage of the analysis is multivariate analysis which yielded odds ratio. The binary logistic regression model was used in this study because the outcome variables are dichotomous or binary, neonatal and infant mortality coded as 0 (Dead) and 1 (Alive) respectively. A single mother is defined in this study as a woman who has either lived with a partner, married before, widowed, separated during the survey periods and has given at least one life live birth. ${ }^{10}$ Ever-marred woman is woman who has been married at least once in their lives although their current marital status may not be married at the time of the survey. ${ }^{11}$ Neonatal mortality is defined as a death during the first 28 days of life (0-27 days). ${ }^{44}$ Infant mortality is defined as the death of a child less than one year of age. ${ }^{44}$ Odds ratio (OR) is defined as the measure of association between an exposure and an outcome. It represents the odds that an outcome will occur given a particular exposure, compared to the odds of the outcome occurring in the absence of that exposure. ${ }^{45}$

\section{Results}

In Table 1 (bivariate analyses of neonatal, infant mortality and Burkinabe women marital status and sociodemographic characteristics), using marital status as the dependent variable, neonatal and infant mortality were significantly associated with marital status. Single mothers were 4.4 times more likely to report neonatal deaths compared to evermarried women (OR 4.4, 95\% Cl 2.701-7.221). With regard to infant mortality, single mothers were 3.7 times more likely than ever-married women to experience infant mortality (OR $3.7,95 \% \mathrm{Cl} 2.714-5.1436$ ). Place or region of residence is significantly associated with neonatal and infant mortality. There were more neonatal and infant mortalities among mothers in the rural areas than in urban areas in Burkina Faso (Table 1).

With regard to number of living children, mothers with six or more children were more likely to have their neonates and infants die (Table 1).

Household wealth index was significantly associated with neonatal and infant mortality. Mothers from rich households were 47 times less likely to have their neonates and infants die (Table 1). A woman's age, numbers of children ever-born, her educational level were significantly associated with neonatal and infant mortality. Burkinabe women with secondary or higher education were 27 times less likely to have their neonatal and infant die compared to the reference group category (Table 1 ). 
Table 1. Bivariate analyses of neonatal, infant mortality and Burkinabe women marital status and sociodemographic characteristics.

\begin{tabular}{|c|c|c|c|c|c|}
\hline \multirow{2}{*}{ Characteristic } & \multicolumn{2}{|c|}{$\begin{array}{c}\text { Total number of women }(17,086) \\
\text { Marital status }\end{array}$} & \multirow{2}{*}{$\begin{array}{l}\text { Odds } \\
\text { ratio }\end{array}$} & \multicolumn{2}{|c|}{$95 \% \mathrm{Cl}$} \\
\hline & $\begin{array}{l}\text { Single mothers } \\
(n=3694) \text { percent }\end{array}$ & $\begin{array}{l}\text { Currently married women } \\
\quad(n=13,392) \text { percent }\end{array}$ & & & \\
\hline \multicolumn{6}{|c|}{ Neonatal births*** } \\
\hline Alive & 21.89 & 78.11 & 1 & & \\
\hline Dead & 5.59 & 94.41 & 4.4 & 2.701648 & 7.221006 \\
\hline \multicolumn{6}{|l|}{ Infant Births*** } \\
\hline Alive & 22.13 & 77.87 & 1 & & \\
\hline Dead & 7.07 & 92.93 & 3.7 & 2.714132 & 5.143623 \\
\hline \multicolumn{6}{|c|}{ Women's age in years $* * * *$} \\
\hline $15-24$ & 45.82 & 54.18 & 1 & & \\
\hline $25-34$ & 5.92 & 94.08 & 13 & 11.90174 & 15.18451 \\
\hline $35-49$ & 6.98 & 93.02 & 11 & 9.999306 & 12.6956 \\
\hline \multicolumn{6}{|c|}{ Women's Educational Level*** } \\
\hline No education & 12.55 & 87.45 & 1 & & \\
\hline Primary & 46.38 & 53.62 & 16 & 0.1533076 & 0.1795539 \\
\hline Secondary/Higher & r 34.48 & 65.52 & 27 & 0.1852949 & 0.4014029 \\
\hline \multicolumn{6}{|c|}{ Socio-economic Status $* * *$} \\
\hline Poor & 16.42 & 83.58 & 1 & & \\
\hline Moderate & 14.58 & 85.42 & 1.1 & 1.019568 & 1.29973 \\
\hline Rich & 29.13 & 70.87 & 47 & 0.4278216 & 0.5337898 \\
\hline \multicolumn{6}{|c|}{ No. of living children*** } \\
\hline $0-5$ & 24.55 & 75.45 & 1 & & \\
\hline $6 \&$ Above & 4.09 & 95.91 & 7.6 & 6.220111 & 9.347222 \\
\hline \multicolumn{6}{|c|}{ No. of children Even born $* * *$} \\
\hline $0-4$ & 6.44 & 93.56 & 1 & & \\
\hline $5-9$ & 4.43 & 95.57 & 1.4 & 1.263889 & 1.744539 \\
\hline $10-14$ & 4.75 & 95.25 & 1.3 & 0.8631875 & 2.207986 \\
\hline \multicolumn{6}{|c|}{ Place of Residence ${ }^{* * *}$} \\
\hline Urban & 11.62 & 88.38 & 1 & & \\
\hline Rural & 3.46 & 96.54 & 3.6 & 3.159015 & 4.26458 \\
\hline
\end{tabular}

Source: Calculated from the 2010 Burkina Faso Demographic and Health Survey $* p<0.05$.

$* * *$ = statistically highly significant.

As shown in Table 2 (bivariate analyses of neonatal, infant mortality and Burundian women marital status and sociodemographic characteristics), neonatal and infant mortality were significantly associated with marital status. Burundian single mothers were more likely to experience neonatal and infant mortality compared to their ever-married counterparts (OR $3.8,95 \% \mathrm{Cl} 2.427-5.9848$ ) and (OR 2.9, 95\% Cl 2.175-3.933). Regarding place or region of 
residence, neonatal and infant mortality was greater in urban areas than in rural areas (Table 2).

Table 2. Bivariate analyses of neonatal, infant mortality and Burundian women marital status and sociodemographic characteristics.

Total number of women (9389)

Marital status

\begin{tabular}{|c|c|c|c|c|c|}
\hline \multirow{2}{*}{ Characteristic } & \multicolumn{2}{|c|}{ Marital status } & \multirow{2}{*}{$\begin{array}{l}\text { Odds } \\
\text { ratio }\end{array}$} & \multicolumn{2}{|c|}{$95 \% \mathrm{Cl}$} \\
\hline & $\begin{array}{l}\text { Single mothers } \\
(n=4128) \text { percent }\end{array}$ & $\begin{array}{l}\text { Currently married women } \\
\qquad(n=5261) \text { percent }\end{array}$ & & & \\
\hline \multicolumn{6}{|c|}{ Neonatal births $* * *$} \\
\hline Alive & 44.35 & 55.65 & 1 & & \\
\hline Dead & 17.29 & 82.71 & 3.8 & 2.42727 & 5.984872 \\
\hline \multicolumn{6}{|l|}{ Infant Births*** } \\
\hline Alive & 44.61 & 55.39 & 1 & & \\
\hline Dead & 21.59 & 78.41 & 2.9 & 2.175612 & 3.933156 \\
\hline \multicolumn{6}{|c|}{ Women's age in years**** } \\
\hline $15-24$ & 71.02 & 28.98 & 1 & & \\
\hline $25-34$ & 20.64 & 79.36 & 3.4 & 8.40438 & 10.57363 \\
\hline $35-49$ & 23.00 & 77.00 & 5.2 & 7.318242 & 9.204597 \\
\hline \multicolumn{6}{|c|}{ Women's Educational Level ${ }^{* * *}$} \\
\hline No education & 30.32 & 69.68 & 1 & & \\
\hline Primary & 53.66 & 46.34 & 3.7 & 0.3443516 & 0.4099608 \\
\hline Secondary/Highe & 44.30 & 55.70 & 5.4 & 0.3966444 & 0.7542746 \\
\hline \multicolumn{6}{|c|}{ Socio-economic Status*** } \\
\hline Poor & 43.06 & 56.94 & 1 & & \\
\hline Moderate & 40.50 & 59.50 & 1.1 & 987001 & 1.250537 \\
\hline Rich & 47.00 & 53.00 & 4.5 & 0.7614117 & 70.9548276 \\
\hline \multicolumn{6}{|c|}{ No of living children $* * *$} \\
\hline $0-5$ & 48.11 & 51.89 & 1 & & \\
\hline 6 \& Above & 11.08 & 88.92 & 7.4 & 6.100432 & 9.07391 \\
\hline \multicolumn{6}{|c|}{ No of children Even born*** } \\
\hline $0-4$ & 18.68 & 81.32 & 1 & & \\
\hline $5-9$ & 14.63 & 85.37 & 1.3 & 1.158651 & 1.552171 \\
\hline $10-14$ & 10.50 & 89.50 & 1.9 & 1.23655 & 3.101414 \\
\hline \multicolumn{6}{|c|}{ Place of Residence $* * *$} \\
\hline Urban & 24.89 & 75.11 & 1 & & \\
\hline Rural & 15.02 & 84.98 & 1.8 & 1.605891 & 2.188822 \\
\hline
\end{tabular}

Source: Calculated from the 2010 Burundi Demographic and Health Survey: ${ }^{*} P<0.05$.

$* * *=$ statistically highly significant.

With regard to education attainment, Burundian women with secondary or higher education were 54 times less likely to have their neonate and infants die compared to the reference group category (Table 2). Number of living children and children ever-born, and household wealth index are significantly associated with marital status (Table 2). 
From Table 3 (bivariate analyses of neonatal, infant mortality and Sierra Leonean women marital status and sociodemographic characteristics), only infant mortality is significantly associated with marital status. Single mothers were 1.5 times more likely to have a child die as an infant compared to ever-married women (95\% Cl 1.195-1.9727).

Table 3. Bivariate analyses of neonatal, infant mortality and Sierra Leonean women marital status and sociodemographic characteristics.

\begin{tabular}{|c|c|c|c|c|c|}
\hline \multirow{2}{*}{ Characteristic } & \multicolumn{2}{|c|}{$\begin{array}{c}\text { Total number of women (7374) } \\
\text { Marital status }\end{array}$} & \multirow{2}{*}{$\begin{array}{l}\text { Odds } \\
\text { ratio }\end{array}$} & \multicolumn{2}{|c|}{$95 \% \mathrm{Cl}$} \\
\hline & $\begin{array}{l}\text { Single Mothers } \\
(n=2001) \text { percent }\end{array}$ & $\begin{array}{l}\text { Currently married women } \\
\quad(n=5373) \text { percent }\end{array}$ & & & \\
\hline \multicolumn{6}{|l|}{ Infant Births*** } \\
\hline Alive & 27.56 & 72.44 & 1 & & \\
\hline Dead & 19.85 & 80.15 & 1.5 & 1.19571 & 1.972746 \\
\hline \multicolumn{6}{|c|}{ Women's age in years $* * * *$} \\
\hline $15-24$ & 54.31 & 45.69 & 1 & & \\
\hline $25-34$ & 13.92 & 86.08 & 7.3 & 6.41913 & 8.421234 \\
\hline $35-49$ & 13.12 & 86.88 & 7.8 & 6.8092 & 9.106861 \\
\hline \multicolumn{6}{|c|}{ Women's Educational Level ${ }^{* * *}$} \\
\hline No education & 12.87 & 87.13 & 1 & & \\
\hline Primary & 51.13 & 48.87 & 1.3 & 0.1256769 & 0.1584647 \\
\hline Secondary/Highe & r 48.28 & 51.72 & 1.5 & 0.1185608 & 0.2111093 \\
\hline \multicolumn{6}{|c|}{ Socio-economic Status*** } \\
\hline Poor & 15.04 & 84.96 & 1 & & \\
\hline Moderate & 18.33 & 81.67 & 3.6 & 0.6581513 & 0.9456303 \\
\hline Rich & 38.05 & 61.95 & 4.5 & 0.2443312 & 0.3401329 \\
\hline \multicolumn{6}{|c|}{ No of living children*** } \\
\hline $0-5$ & 28.79 & 71.21 & 1 & & \\
\hline $6 \&$ Above & 8.14 & 91.86 & 4.5 & 3.382376 & 6.160623 \\
\hline \multicolumn{6}{|c|}{ No of children Even born $* * *$} \\
\hline $0-4$ & 16.99 & 83.01 & 1 & & \\
\hline $5-9$ & 10.24 & 89.76 & 1.7 & 1.50101 & 2.144194 \\
\hline $10-14$ & 10.78 & 89.22 & 1.9 & 0.9010126 & 53.182288 \\
\hline \multicolumn{6}{|c|}{ Place of Residence ${ }^{* * *}$} \\
\hline Urban & 22.96 & 77.04 & 1 & & \\
\hline Rural & 10.00 & 90.00 & 2.6 & 2.31721 & 3.105129 \\
\hline
\end{tabular}

Source: Calculated from the 2010 Sierra Leone Demographic and Health Survey: ${ }^{*} P<0.05$.

$* * *=$ statistically highly significant.

Sierra Leonean women with higher education were more likely to have their neonates and infants survive compared to the reference group category. With regard to age, the more advanced in age a woman is, the more likely for her to have her neonate and infant die. 
Sierra Leonean women from rich households were 28 times more likely to have their neonates and infants survive compared to the reference group category (Table 3 ).

In Table 4 (adjusted odds ratios from logistic regression of neonatal, infant mortality and Burkinabe women marital status), a further in-depth statistical analyses using multivariate logistic regression found infant and neonatal mortality significantly associated with Burkinabe women marital status. Burkinabe single mothers were 1.3 times more likely to have their child die as a neonate compared to their married counterpart. With regard to infant mortality, Burkinabe single mothers were 3.2 times likely to have their child die as an infant compared to their ever-married counterparts.

Table 4. Adjusted odds ratios from logistics regression of neonatal, infant mortality and Burkinabe women marital status.

\begin{tabular}{|c|c|c|}
\hline \multicolumn{2}{|c|}{ Characteristics Odds ratio } & $95 \% \mathrm{Cl}$ \\
\hline \multicolumn{3}{|c|}{ Neonatal mortality*** } \\
\hline Alive & 1 & \\
\hline Dead & 1.3 & 0.73334742 .657945 \\
\hline \multicolumn{3}{|c|}{ Infant Mortality*** } \\
\hline Alive & 1 & \\
\hline Dead & 3.2 & $2.110672 \quad 4.879617$ \\
\hline
\end{tabular}

Source: Calculated from the 2010 Burkina Faso Demographic and Health Survey: ${ }^{*} P<0.05$. *** = statistically highly significant.

As shown in Table 5 (adjusted odds ratios from logistic regression of Burkinabe women marital status and their sociodemographic characteristics), the logistic regression model for Burkinabe women marital status and their sociodemographic characteristics, women's age, educational attainment, socio-economic status, number of living children and number of children ever-born and place or region of residence were significantly associated with neonatal and infant mortality. Women who had more than five children had more likelihood of having their neonates and infants die compared to mothers with fewer children. Considering household wealth index, mothers who belonged to rich households were 1.6 times more likely to have their neonates and infants survive compared to mothers who are from poor households. 
Table 5. Adjusted odds ratios from logistics regression of neonatal, infant mortality and Burkinabe women sociodemographic characteristics.

Characteristics Odds ratio

$95 \% \mathrm{Cl}$

$\begin{array}{llll}\text { Women's age in years**** } & & \\ 15-24 & 1 & & \\ 25-34 & 1.8 & 1.464541 & 2.218048 \\ 35-49 & 6.5 & 0.516416 & 0.8193587\end{array}$

Women's Educational Level***

No education 1

$\begin{array}{lll}\text { Primary } & 3.5 & 0.37940810 .5449254\end{array}$

Secondary/Higher $4.8 \quad 0.56456985 .998487$

Socio-economic Status***

Poor $\quad 1$

$\begin{array}{llll}\text { Moderate } & 1.7 & 1.319397 & 2.134004\end{array}$

Rich $\quad 2.3 \quad 1.212985 \quad 2.015401$

No of living children***

0-5 1

6 \& Above $\quad 1.3 \quad 1.039701 \quad 1.794743$

No of children Even born***

0-4 1

$\begin{array}{llll}5-9 & 1.4 & 1.106635 & 1.762712\end{array}$

Place of Residence ${ }^{* * *}$

Urban 1

$\begin{array}{llll}\text { Rural } & 2.9 & 2.353702 & 3.50829\end{array}$

Source: Calculated from the 2010 Burkina Faso Demographic and Health Survey $* P<0.05$.

$* * *=$ statistically highly significant.

From Table 6 (adjusted odds ratios from logistic regression of neonatal, infant mortality and Burundian women marital status), logistic regression analyses showed that Burundian single mothers were 1.7 times more likely to have their babies die as a neonate than their evermarried mothers' counterparts. Also, infants of single Burundian mothers were 2.2 times more likely to die than infants of ever-married Burundian women.

Table 6. Adjusted odds ratios from logistics regression of neonatal, infant mortality and Burundian women marital status.

\begin{tabular}{lccc}
\multicolumn{2}{l}{ Characteristics Odds ratio } & \multicolumn{2}{c}{$95 \%$ Cl } \\
\cline { 2 - 4 } \multicolumn{2}{l}{ Neonatal mortality*** } & & \\
Alive & 1 & & \\
Dead & 1.7 & 0.9242361 & 3.040613 \\
Infant Mortality*** & & & \\
Alive & 1 & & \\
Dead & 2.2 & 1.55156 & 3.40368
\end{tabular}

Source: Calculated from the 2010 Burundi Demographic and Health Survey: ${ }^{*}<0.05$.

$* * *=$ statistically highly significant. 
In Table 7, when all the variables were controlled for simultaneously, women's age, educational attainment, place of residence, socio-economic status, number of living children and number of children ever born were significantly associated with neonatal and infant mortality. Table 8 shows the adjusted odds ratios from logistic regression of Sierra Leonean women and sociodemographic characteristics.

Table 7. Adjusted odds ratios from logistic regression of neonatal, infant mortality and Burundian women sociodemographic characteristics.

\begin{tabular}{lccc}
\multicolumn{2}{c}{ Characteristics } & Odds ratio & \multicolumn{1}{c}{$95 \% \mathrm{Cl}$} \\
\cline { 3 - 4 } Women's age in years**** & & \\
$15-24$ & 1 & & \\
$25-34$ & 1.2 & 1.015177 & 1.510565 \\
$35-49$ & 3.6 & 2917592 & 0.4524248
\end{tabular}

Women's Educational Level***

No education 1

Primary $\quad 1.1 \quad 9232948 \quad 1.269649$

Secondary/Higher $5.2 \quad 2.21443 \quad 12.54491$

Socio-economic Status***

Poor 1

Moderate $\quad 1.6 \quad 1.2954461 .867255$

Rich $\quad 2.3 \quad 1.9310542 .94516$

No of living children***

$0-5 \quad 1$

6 \& Above $\quad 1.9 \quad 1.4507022 .423013$

No of children Even born***

0-4 1

$\begin{array}{lll}5-9 & 2.0 & 1.6351672 .453789\end{array}$

Place of Residence***

Urban 1

$\begin{array}{lll}\text { Rural } & 2.8 & 2.3076653 .455764\end{array}$

Source: Calculated from the 2010 Burundi Demographic and Health Survey: ${ }^{*} p<0.05$.

$* * *=$ statistically highly significant. 
Table 8. Adjusted odds ratios from logistic regression of Sierra Leonean women and sociodemographic characteristics.

\begin{tabular}{|c|c|c|c|}
\hline \multirow{2}{*}{$\begin{array}{l}\text { Characteristics } \\
\text { Women's age*** }\end{array}$} & \multirow{2}{*}{$\begin{array}{l}\text { Odds ratio } \\
*\end{array}$} & \multicolumn{2}{|c|}{$95 \% \mathrm{Cl}$} \\
\hline & & & \\
\hline $15-24$ & 1 & & \\
\hline $25-34$ & 2.3 & 1.942573 & 2.840174 \\
\hline $35-49$ & 1.9 & 1.541898 & 2.375742 \\
\hline \multicolumn{4}{|c|}{ Women's Educational Level ${ }^{* * *}$} \\
\hline No Edu & 1 & & \\
\hline Primary & 2.4 & 3145186 & 0.4392117 \\
\hline Secondary/Highe & 3.7 & 1683796 & 0.3652193 \\
\hline \multicolumn{4}{|c|}{ Socio-economic Status $* * *$} \\
\hline Poor & 1 & & \\
\hline Moderate & 3.2 & 6862513 & 1.137644 \\
\hline Rich & 5.6 & 0.5702917 & 1.001807 \\
\hline \multicolumn{4}{|c|}{ No of living children ${ }^{* * *}$} \\
\hline $0-5$ & 1 & & \\
\hline $6 \&$ Above & 1.5 & 1.038835 & 2.173604 \\
\hline \multicolumn{4}{|c|}{ No of children Even born $* * *$} \\
\hline $0-4$ & 1 & & \\
\hline $5-9$ & 1.8 & 0.86362 & 1.355627 \\
\hline \multicolumn{4}{|c|}{ Place of Residence*** } \\
\hline Urban & 1 & & \\
\hline Rural & 1.6 & 1.28827 & 1.939514 \\
\hline
\end{tabular}

Source: Calculated from the 2010 Sierra Leone Demographic and Health Survey: ${ }^{*} P<0.05$. $* * *=$ statistically highly significant.

\section{Discussion}

The findings of the study showed increased risks of neonatal and infant mortality with single mothers compared with those of ever-married mothers. Factors such as stress and economic hardship, lack of social support, could have been important in accounting for increased risks of neonatal and infant mortality with single mothers.

For instance, stress can weaken a mother's immune system when $\mathrm{CRH}$, a hormone that makes one more focused and ready to spring into action, is over secreted. ${ }^{46}$ Research shows that single mothers experience more stressful life events than do married mothers. ${ }^{47}$

The mother's stress can also affect the child, both directly and indirectly. Studies reveal that parenting stress leads to a stricter disciplinary style and less nurturing behaviours toward the child. ${ }^{48}$ Mothers who are dissatisfied with their employment status enjoy their children less, are less confident as parents, and have more difficulty controlling their children. ${ }^{49}$ These parental behaviours mediate stress into negative influence on the development of 
the child. Moreover, a recent study shows that parenting stress has a direct impact, independent from parenting practices, on preschool children's social competence ${ }^{50}$

A single mother who juggles many responsibilities more readily falls sick, creating an additional strain. For example, a study of various family structures found that single mothers had somewhat lower well-being than did married mothers. ${ }^{51}$ and 52 Single mothers face significant difficulty in providing quality child care for their children compared to married women. ${ }^{53}$ One study ${ }^{47}$ found that a combination of parenting single handedly, financial tension, and strain of over load often lead to neglect of children.

The findings of the study showed a clear effect of maternal age on the risk of neonatal and infant mortality in the three countries. This finding suggest that older women may be at increased risk of neonatal and infant mortality due to common disease associated with older age, such as diabetes and hypertension and complications of pregnancy, such as abruption, which are also associated with increasing maternal age. This finding supports the research findings of Astolfi and Zonta, ${ }^{54}$ who found that the risk of infant mortality was high in older women (35 years and above).

With regard to neonates and infants born to mothers living in rural and urban areas, women in rural were more likely to have their children die as neonates and infants compared to their urban counterparts. This supports ${ }^{1}$ argument that cities and towns tend to have lower mortality rates than rural areas, possibly because people residing in rural areas are less educated than their urban counterparts and the distribution of amenities favours the urban areas. Access to drinkable water in the rural areas and easy access to health-care services by members of the community could also reduce risks of neonatal and infant mortality.

Availability and access to drinkable water within the community could prevent children from contracting avoidable infections and water-borne diseases, such as diarrhoeal disease and other forms of infections. This study points to the importance of good infrastructure for child survival. This result has established an elevated risk of neonatal and infant mortality for communities in poor socio-economic contexts. This finding also establishes one of the reasons rural areas tend to have poorer child health outcomes than their urban counterparts.

Wealth index covariate is another important determinant of infant and child mortality that was established in this study. Mothers of the poor wealth quintile reported the highest rate of neonatal and infant mortality in the three countries. This corroborates previous findings, which established that socio-economic factors such as education, occupation and wealth index are more important in infancy than childhood. ${ }^{55}$ This inequity is a composite of many factors, including economic access to antibiotics and other drugs from private venders, where a wealthy family often has a better access in addition to better nutrition and improved housing since access to antibiotics plays an important role in newborn survival.

Maternal educational background was another predictor of neonatal and infant mortality both bivariate and multivariate level across the three countries. Mothers with secondary/higher education were less likely to have their neonates and infants die compared to mothers with no educations. This supports previous studies showing that 
maternal and paternal education are among the most important factors associated with infant survival. ${ }^{1}$

With regard to the number of living children at both bivariate and multivariate level across the three countries. Mothers with more than 1-4 children in households were more likely to have their neonates and infants die as neonates and infant. This finding supports other studies; ${ }^{1 \text { and } 21}$ their study found that the number of living children and children ever-born are among the most important factors associated with infant survival. The result suggests that the propensity for neonates and infants to survive declines as the number of living children increases.

\section{Conclusion}

Results from the logistic regression models across the three countries showed maternal marital status, maternal age, place of residence, number of children ever-born, maternal educational background were statistically associated with neonatal and infant mortality in Sierra Leone, Burkina Faso, and Burundi. The findings of this study have expanded on earlier research that implicated malnutrition, infection, dehydration and diarrhoea in neonatal and infant mortality in SSA. As rate of neonatal and infant mortality remains high in SSA, single mothers-to-be may be targeted with the goal of educating, increasing awareness, and providing resources for proper obstetrical and maternal care.

\section{Author statements}

\section{Ethical approval}

This study was based on secondary analysis of an existing dataset with all participant identifiers removed. For Burundi, the survey instruments received ethical approval from the Institut de Statistiques et d'Études Économiques du Burundi (ISTEEBU)/Ministère des Finances et de la Planification du Développement Economique, and the Institut National de Santé Publique (INSP)/Ministère de la Santé Publique et de la Lutte contre le Sida. While for Sierra Leone, the survey instruments received ethical approval from the Statistics Sierra Leone (SSL) and the Ministry of Health and Sanitation (MOHS). For Burkina Faso, the survey instruments received ethical approval from the Institut National de la Statistique et de la Démographie (INSD) of the Ministry of Economy and Plan (MOEP) and the Ministry of Health $(\mathrm{MOH})$. All of the selected countries were supported by the Ethics Committee of the Opinion Research Corporation of Macro International Inc., Calverton, MD, USA. Permission to use the datasets of the selected countries for this study was obtained from ICF Macro Inc.

\section{Funding}

No funding was received for the study.

\section{Competing interests}

No competing interest. 


\section{References}

1. Izugbara C. Whose Child is dying? Household characteristics and under-five mortality in Nigeria. South Afr J Child Health 2014;8(1):16-22.

2. Sania $A$, et al. The contribution of preterm birth and intrauterine growth restriction to infant mortality in Tanzania. Paediatr Perinat Epidemiol 2014;28(1):23-31.

3. Aigbe GO, Zannu AE. Differentials in infant and child mortality rates in Nigeria: evidence from the six geopolitical zones. Inter J Hum Soc Sci 2012 2000;2(16):14. 206.

4. Ogunjuyigbe PO. Under-five mortality in Nigeria: perception and attitudes of the Yorubas towards the existence of Abiku". Demogr Res 2004;11(2):43-56.

5. Hallett TB, et al. Measuring and correcting biased child mortality statistics in countries with generalized epidemics of HIV infection. Bull World Health Organ 2010;88(10):761-8.

6. Griffiths $P$, et al. A tale of two continents: a multilevel comparison of the determinants of child nutritional status from selected African and Indian regions. Health Place 2004;10(2):183-99.

7. Garenne $\mathrm{M}$, Ronsmans $\mathrm{C}$, Campbell $\mathrm{H}$. The magnitude of mortality from acute respiratory infections in children under 5 years in developing countries. World Health Stat $Q$ 1992;45:180.

8. Hargreaves S. Time to right the wrongs: improving basic health care in Nigeria. Lancet 2002;359(9322):2030-5.

9. Van Malderen $\mathrm{C}$, et al. Contributing determinants of overall and wealth-related inequality in under-5 mortality in 13 African countries. J Epidemiol Community Health 2013;67(8):667-76.

10. Bumpass LL, Raley RK. Redefining single-parent families: cohabitation and changing family reality. Demography 1995;32(1):97-109.

11. United Nations. The millennium development goals. United Nations. Available from: http://www.un.org/millenniumgoals; 2008 [accessed 11 February 2016].

12. UNICEF. Committing to child survival: a promise renewed (progress report 2012). New York: UNICEF; 2013.

13. Wand H, Whitaker C, Ramjee G. Geoadditive models to assess spatial variation of HIV infections among women in Local communities of Durban, South Africa. Int J Health Geogr 2011;10(1):28.

14. Kanjala C, et al. Spatial and temporal clustering of mortality in Digkale HDSS in rural northern South Africa. Glob Health Action Suppl 2010;1:59-63.

15. Schell CO, et al. Socioeconomic determinants of infant mortality: a worldwide study of 152 low-, middle-, and high-income countries. Scand J Public Health 2007;35(3):288e97.

16. Sastry N. What explains rural-urban differentials in child mortality in Brazil? Soc Sci Med 1997;44(7):989-1002.

17. Rutstein SO. Factors associated with trends in infant and child mortality in developing countries during the 1990s. Bull World Health Organ 2000;78(10):1256-70.

18. Wang L. Determinants of child mortality in LDCs: empirical findings from demographic and health surveys. Health policy 2003;65(3):277-99.

19. Chatterjee $S$, Saha S. A study on knowledge and practice of mothers regarding infant feeding and nutritional status of under-five children attending immunisation clinic of a medical College. Internet J Nutr Wellness 2008;5(1). 
20. Chen A, Rogan WJ. Breastfeeding and the risk of postneonatal death in the United States. Pediatrics 2004;113(5):e435-9.

21. Rajaratnam JK, et al. Neonatal, postneonatal, childhood, and under-5 mortality for 187 countries, 1970-2010: a systematic analysis of progress towards Millennium Development Goal 4. Lancet 2010;375(9730):1988-2008.

22. Briggs GG, Freeman RK, Yaffe SJ. Drugs in pregnancy and lactation: a reference guide to fetal and neonatal risk. Lippincott Williams \& Wilkins; 2012.

23. Akinyemi JO, Bamgboye EA, Ayeni O. New trends in under-five mortality determinants and their effects on child survival in Nigeria: a review of childhood mortality data from 19902008. Afr Popul Stud 2013;27(1):25-42.

24. Osuorah $D$, et al. Effect of maternal exposure to intimate partner violence on under-five mortality in Nigeria. Nigerian Journal of Paediatrics. 2012;39(3):97-104.

25. Silverman JG, et al. Gender-based disparities in infant and child mortality based on maternal exposure to spousal violence: the heavy burden borne by Indian girls. Archives Pediatr Adolesc Med 2011;165(1):22-7.

26. Ziaei S, Naved RT, Ekstr€om EC. Women's exposure to intimate partner violence and child malnutrition: findings from demographic and health surveys in Bangladesh. Maternal Child Nutr 2012;10:347-59.

27. Kiernan K, Pickett KE. Marital status disparities in maternal smoking during pregnancy, breastfeeding and maternal depression. Soc Sci Med 2006;63(2):335-46.

28. Garenne M, Tollman S, Kahn K. Premarital fertility in rural South Africa: a challenge to existing population policy. Stud Fam Plan 2000;31(1):47-54.

29. Steele F, Sigle-Rushton $W$, Kravdal $\varnothing$. Consequences of family disruption on children's educational outcomes in Norway. Demography 2009;46(3):553-74.

30. Osborne C, Berger LM, Magnuson K. Family structure transitions and changes in maternal resources and well-being. Demography 2012;49(1):23-47.

31. Gage AJ, Njogu W. Gender inequalities and demographic behavior: Ghana/Kenya; 1994.

32. Cnattingius $S$. The epidemiology of smoking during pregnancy: smoking prevalence, maternal characteristics, and pregnancy outcomes. Nicotine Tob Res 2004;6(Suppl. 2):S12540.

33. Izugbara C. Household characteristics and unintended pregnancy among ever-married women in Nigeria. Soc Med 2013;8(1):4-10.

34. Clark S, Hamplová D. Single motherhood and child mortality in sub-Saharan Africa: a life course perspective. Demography 2013;50(5):1521-49.

35. Buvinic M, Gupta GR. Female-headed households and female-maintained families: are they worth targeting to reduce poverty in developing countries? Econ Dev Cult change 1997;45(2):259-80.

36. Posel DR. Who are the heads of household, what do they do, and is the concept of headship useful? an analysis of headship in South Africa. Dev South Afr 2001;18(5):651-70.

37. Brown GW, Moran PM. Single mothers, poverty and depression. Psychological medicine. 1997;27(01):21-33.

38. Gabel S. Behavioral problems in sons of incarcerated or otherwise absent fathers: the issue of separation. Fam Process 1992;31(3):303-14.

39. Edleson JL. The overlap between child maltreatment and woman battering. Violence against women 1999;5(2):134-54. 
40. Farrington DP. Developmental criminology and risk-focused prevention. The Oxford handbook of criminology. 2002;3:657-701.

41. Hertzman C, C.C.f.P.A.B. Office. Making early childhood development a priority: lessons from Vancouver. Canadian Centre for Policy Alternatives, BC Office; 2004.

42. Cleves M. An introduction to survival analysis using Stata. Stata Press; 2008.

43. Izugbara C. Socio-demographic risk factors for unintended pregnancy among unmarried adolescent Nigerian girls. South Afr Fam Pract 2015;57(2):121-5.

44. Bryce J, et al. WHO estimates of the causes of death in children. Lancet 2005;365(9465):1147-52.

45. Vittinghoff E, et al. Predictor selection. In: Regression methods in biostatistics. Springer; 2012. p. 395-429.

46. Alonge 0 . The effect of maternal psychosocial stress on infant birth weight: a retrospective cohort study. Drexel University; 2012.

47. RANI NI. Child care by poor single mothers: study of mother-headed families in India. J Comp Fam Stud; 2006::75-91.

48. Halpern LF, Brand KL, Malone AF. Parenting stress in mothers of very-low-birth-weight (VLBW) and full-term infants: a function of infant behavioral characteristics and child-rearing attitudes. J Pediatr Psychol 2001;26(2):93-104.

49. DeHart G, Sroufe LA, Cooper RG. Child development: its nature and course. McGraw-Hill Companies; 2000.

50. Webster-Stratton C. Stress: a potential disruptor of parent perceptions and family interactions. J Clin Child Psychol 1990;19(4):302-12.

51. Thomson E, Hanson TL, McLanahan SS. Family structure and child well-being: economic resources vs. parental behaviors. Soc Forces 1994;73(1):221-42.

52. Lansford JE, et al. Does family structure matter? a comparison of adoptive, two-parent biological, single-mother, stepfather, and stepmother households. J Marriage Fam2001;63(3):840-51.

53. Weinraub $M$, Wolf $B M$. Effects of stress and social supports on mother-child interactions in single-and two-parent families. Child Dev; 1983::1297-311.

54. Astolfi P, Zonta L. Risks of preterm delivery and association with maternal age, birth order, and fetal gender. Hum Reprod 1999;14(11):2891-4.

55. Wells JC. Natural selection and sex differences in morbidity and mortality in early life. $J$ Theor Biol 2000;202(1):65-76. 